\title{
Research on the Spatial Distribution Difference of Compulsory Education between China and Australia
}

\author{
https://doi.org/10.3991/ijet.v15i04.11702 \\ Saidong Lv ${ }^{(凶)}$, Yujun Pan \\ Yunnan Normal University, Kunming, China \\ saidonglveynnu.edu.cn
}

\begin{abstract}
This study collected regional data from 31 provinces in China and 8 states and territories in Australia in 2016. The study used the descriptive and analytical approach to analyze the results. Also, it used the inductive approach, the descriptive statics analysis and the SPSS to analyze data. it found that the distribution of compulsory education bears both similarities and differences in the two countries. In terms of similarities,there are certain regional differences in the teachers' faculty of compulsory education in the two countries, and an unbalanced distribution of teachers has emerged. The difference is that although China's compulsory education has rqpidly, the teachers and funds of compulsory education lag far behind Australia, and the Regional imbalance is more serious in China than that in Australia.In other words, if there is a rapidly increasing population somewhere, and the nuers of teachers aren't keeping up with this in China.
\end{abstract}

Keywords - Compulsory education, spatial distribution, descriptive statics analysis, Regional gap

\section{Introduction}

Compulsory education was developed in accordance with the law requiring all children to receive schooling. Compulsory education requires the state and family to guarantee ensure the education of their children, and those families who fail to perform their rights and obligations should be punished by law [1]. There is extensive research on the effects of compulsory education, mostly in developed countries [2].Compulsory education has become common policy world-wide in the second part of the twentieth century, and China is no exception. In April 1986, the issue of the Compulsory Education Law of People's Republic of China was issued, which marks the new stage of the popularization and development of compulsory education in China. In 2006, the items of Compulsory Education Law of the Peoples Republic of China legilation increased from 18 to 63, The law makes regulations concerning students, schools, teachers, teaching work, financial support and legal responsibility. It not only emphasizes the public welfare, unity and mandatory principles of compulsory education, but also takes the balanced development as the direction and principle of the development of compulsory education, and makes it clear that 
compulsory education is fully integrated into the scope of financial security. The county compulsory education management system is written into the legal system,such as Germany, France and England. and compulsory education quality education is promoted through the legal provisions. The promulgation and implementation of the newly revised Law of Compulsory Education provides a new development paradigm, management mechanism and system support for the development of compulsory education in China, and provides legal guarantee for the high quality development of compulsory education [3].

We have to admit that, because of the imbalance of economic development and the contradiction between the two kinds structure of urban and rural areas, the educational gap between urban and rural areas, between districts and counties and between schools persists [4].In order to meet expected standards of high quality compulsory education, after solving the "learning" problem of the school-age children, the goal of "learning to be better" is further realized. Since the new century, the party and the state government have taken "a balanced development" as the new goal of the development of compulsory education in China. In the notice issued by the Ministry of education in February 2002 on Strengthening the Management of School Running in Basic Education, it was proposed to "promote the balanced development of schools in the compulsory education stage" [5]. In June 2006, "balanced development" as a requirement for the development of compulsory education was clearly written into the compulsory education law (Amendment). In January 2010, the Ministry of Education issued the comments on the implementation of Scientific Outlook on Development to further promote the balanced development of compulsory education, emphasizing "the importance of promoting balanced development as an important task for the reform and development of compulsory education" [6]. In July of the same year, the Central Committee of the Communist Party of China and the State Council issued the outline of the national medium and long term education reform and development plan (2010-2020 years), and clearly stated that "balanced development is the strategic task of compulsory education", which requires "a balanced development of compulsory education" [7]. In the decision on accelerating the development of Ethnic Education by the State Council in August 2015, the "compulsory education for balanced development" was put forward again, emphasizing vigorously promoting the standardized construction of compulsory education schools in ethnic areas, improving the basic conditions of schools which in poor areas of compulsory education, and narrowing the gap between urban and rural areas. In July 2016, the State Council issued a number of opinions on the Overall Promotion of the Integrated Reform and Development of Compulsory Education in Urban and Rural Areas of the County, and pushed ten measures [8]. By 2020, the balanced development of compulsory education in the country and the equalization of basic public education services in urban and rural areas were basically realized.

Regional disparities of compulsory education is a universal phenomenon not only in China but also in many developing countries. Kinda Wazzan pointed out that the existing of the problem of inequality and adequacy spatial distribution between different wards of Lattakia [9]. In Syria, where some of wards are very advantaged at the neglect of others very disadvantaged and deficient. In these wards we can 
investigate about the rates of overcrowding or school dropout rates and the effects on the quality of education that weaken the human and economic development of the urban society, not only in these wards but also in all the city.

An increase in the human capital level can have negative effects on the spatial distribution of population because it fosters agglomeration [10], and the distribution of the population affects the distribution of compulsory education.Certainly, increasing human capital investment in less-developed areas may be an effective way to both increase intergenerational educational mobility and reduce regional inequality in education. Hence, understanding the reform effects on longer-term outcomes is necessary for the estimation of the internal rate of return on the compulsory education subsidies. The government focus ought to now shift towards improving the quality and increasing funding for compulsory education.

The Australian education system looks like a hybrid of British and American features, with an overlay of characteristics distinctively Australian [11]. In 2009, all Australian states signed the 'National Partnership Agreement on Youth Attainment and Transitions' [12]. This coordination of policy committed each state's particular educational jurisdiction to a uniform effort to increase the number of students participating in schooling till Year 12, training or ongoing employment [13]. Historically, six states (NSW, Victoria, Queensland, Tasmania, South Australia, and Western Australia) and two territories (the Northern Territory and the Australian Capital Territory) of Australia have had different ages for compulsory participation in education because each is responsible for its own public and, to some extent, private schooling systems. As of the start of 2010, however, all young people under 17 years of age must be enrolled in approved education or training, engaged in full-time work, or some combination of these [14]. many schools find that have little opportunity or too much competition and limited pathways. Whole school change is restricted by inadequate resourcing in some schools and by insufficient social networks in their communities [15], The gap between the developed and the underdeveloped areas is clear.

Through this study, the researchers hope that we can find different spatial distribution of compulsory education between China and Australia. Certainly, the researchers' aim is that solutions may be provided to the education management department when it comes to the fair distribution of education resources.

\section{Methods}

\subsection{Sources of data}

All research data are from China and Australia government sources in 2016 and the scope of two countries' data is mainly about compulsory education stage (in public school). The data mainly comprise numbers of students (age 6-15 years old), teachers and government finances each country. The Chinese data pertains to 31 provinces of China but excluding Taiwan, Macao and Hong Kong, from the Education Statistical Yearbook in China 2016, China Statistical Yearbook 2016 and Tabulation on the 
2010 Population census of the peoples replubuc of China. The Australian data originate from Australian Bureau of Statistics 2016 that includes 8 states ad territories: New South Wales, Victoria, Queensland, South Australia, Western Australia, Tasmania, Northern Territory, Australian Capital Territory.

\subsection{Data processing}

In order to make the compulsory education (CE) of two countries more scientific and reasonable, the data were processed in this study. All needed data were conversion, tallied and interpreted. Let $\mathrm{A}=\{$ China,Australia $\}$,define the following equation:

$$
\begin{aligned}
\mathrm{R}_{s} & =\frac{N_{s}}{N_{p}} \mathrm{~s} \in \mathrm{A} \\
\mathrm{R}_{t} & =\frac{N_{t}}{N_{p}} \mathrm{t} \in \mathrm{A} \\
\mathrm{R}_{s t} & =\frac{N_{t}}{N_{s}} \mathrm{st} \in \mathrm{A} \\
\mathrm{C}_{p s} & =\frac{C}{N_{s}} \mathrm{ps} \in \mathrm{A}
\end{aligned}
$$

Where $\mathrm{R}_{s}$ is number of students ratio, $N_{s}$ is the number of students , and $N_{p}$ is sum of population. $\mathrm{R}_{t}$ is number of teachers ratio, $N_{t}$ is the number of teachers. $\mathrm{R}_{s t}$ is student to teaching Staff Ratio, $\mathrm{C}_{p s}$ is annual government finance per-students funds. $\mathrm{C}$ is count of Government Finance . Where $\mathrm{p}$ is a constant.

\subsection{Instruments}

The data were computed using a statistical software which is called SPSS (Statistical Product and Service Solutions) with Descriptive Statistics,such as Mean, Standard Deviation and Variance.

Meanwhile, this study also developed spatial distribution of maps using ArcMap10.2.2. ArcMap is a user desktop component, which has powerful functions of map making, spatial analysis, spatial data analysis and so on.It is a system of GIS developed by ESRI (Environment System Research Institute) in 1978.

\subsection{Data analysis}

The data of the research mainly comprise of two parts: part one is the Chinese number of students, teachers and government finance; part two is Australian number of students, teachers and government finance. All data are processed and transformed,at the same time, All data are statisticed with Descriptive Statistic analysis.

Chinese CA data descriptive statistics can be seen in Table 1 and Table 2. There are 31 provices covered in this research, so from Table 1 and Table 2 we can see 
clearly that the Chinese total data is 31 items and valid data also is 31 items, no missing data. Australian total data is 8 items and valid data also is 8 items,also no missing data in Australia.

The number of Chinese students is illustrated by Table 1 and number of Australian students is illustrated by Table 2.The minimum number of students is 177174 and maximum number of students is 5283290 in China. Meanwhile, in Australia the number of students is 30050 and maximum number of students is 831963 . The range is so large that there are big gaps on student's quantity for two countries from two tables. In other words, the data of students in two countries have large discrete degree. From another perspective, the smaller the standard deviation, the more aggregated. The larger the standard deviation, the more discrete the data. We can know clearly that the standard deviation in Table1 is much larger than in Table 2, so the degree of discreteness on number of students in China is larger than that of Australia, This also illustrates the population is more unevenly distributed in China than in Australia, the number of students in all provinces of Chinnese varies greatly. And how large is the degree of dispersion? We can find out results from variance of Ns. China variance of Ns is 1801863834093.070 and Australia variance of Ns is 94991967816.411.From this result we know that all the provinces in two countries have a large degree to deviate from the mean.

It also can be seen from Table 1 and Table 2, the gap between the maximum and minimum number of students, the number of teachers and the total population in China are big, and the standard deviation also is large in Australia, These shows perprovince has large degree of dispersion in two countries.

Table 1. Descriptive statistics of Chinese Compulsory Education Data

\begin{tabular}{|l|c|c|c|c|c|c|}
\hline & N & Min & Max & Mean & Std & Variance \\
\hline $\mathrm{Ns}$ & 31 & 177174 & 5283290 & 1841836 & 1342335.217 & 1801863834093.070 \\
\hline $\mathrm{Nt}$ & 31 & 30647 & 787942 & 289196.03 & 190850.142 & 36423776613.432 \\
\hline $\mathrm{Np}$ & 31 & 3002165 & 104320459 & 42993899 & 27635084.306 & 763697884611603 \\
\hline $\mathrm{C}$ & 31 & 1056 & 11064 & 4856.42 & 2438.637 & 5946951.318 \\
\hline ValidN & 31 & & & & & \\
\hline
\end{tabular}

Table 2. Descriptive statistics of Australian Compulsory Education Data

\begin{tabular}{|l|c|c|c|c|c|c|}
\hline & N & Min & Max & Mean & Std & Variance \\
\hline $\mathrm{Ns}$ & 8 & 30050 & 831963 & 327124.13 & 308207.670 & 94991967816.411 \\
\hline $\mathrm{Nt}$ & 8 & 5860 & 132538 & 58358.38 & 52097.953 & 2714196709.125 \\
\hline $\mathrm{Np}$ & 8 & 246 & 7895 & 3086.75 & 2956.544 & 8741153.929 \\
\hline $\mathrm{C}$ & 8 & 839 & 13755 & 5659.38 & 4919.598 & 24202446.554 \\
\hline ValidN & 8 & & & & & \\
\hline
\end{tabular}




\section{Results and Discussion}

Based from the result of Fig. 1, the number of students accounts for 11 percent of the total population in CE in China. The number of students accounts for 11 percent of the total population in CE in Australia. From these data, the proportion of students in CE in China is higher than that in Australia. Meanwhile, the proportion of teachers accounts for 2 percent of the total population in compulsory education in China The count of teachers accounts for 1 percent of the total population in CE in Australia. The proportion of students in China is $11 \%$ higher than that in Australia in CE, but the proportion of teachers is only $1 \%$ higher than that in Australia. At the same time, in Fig. 2, Student to Teacher Ratio is 6.4:1 in China, compared to 5.6:1 in Australia. Chinese count of teachers is less than in Australia. Compared with Australia, Fig.1 and Fig. 2 simultaneously show Chinese is short of teachers in CE. China has not invested enough funds in the CE stage, so next step is for the Chinese government to increase the numbers of teachers in $\mathrm{CE}$. In order to increase the qualified of $\mathrm{CE}$ teachers and attract new teacher resources to join the ranks of CE, the government should improve the salary level of teachers, formulate various incentive measures, and provide an improved working environment for teachers.

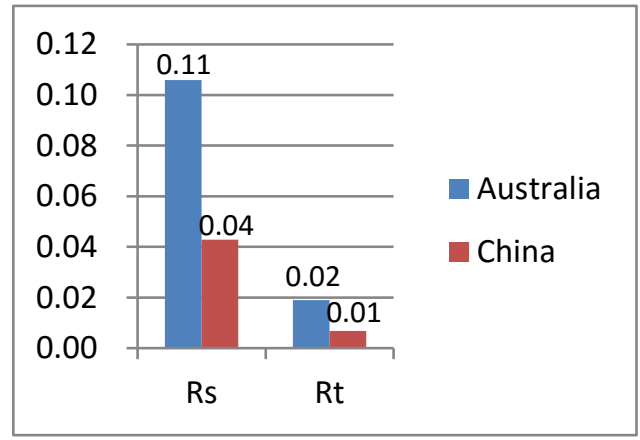

Fig. 1. Total comparison of Rs and Rt.

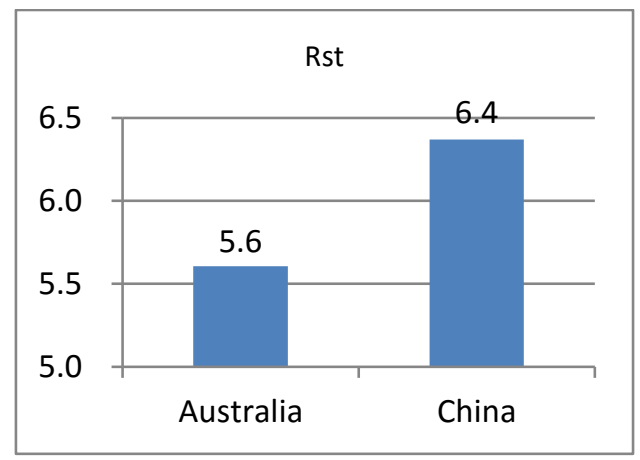

Fig. 2. Total comparison of Rst. 
Fig. 3 shows a comparison on government finance annually to students of CE period between China and Australia. The government finance includes central financial allocations and local government appropriations. From the annual average education expenditure invested by two governments, The Australian government's investment in $\mathrm{CE}$ far exceeds that of China. Fig. 1 also shows that Australia has a higher degree of concern for $\mathrm{CE}$. $\mathrm{CE}$ as a public product, the importance of government is the most fundamental guarantee for optimizing the allocation of resources in CE. Increasing government investment in CE is of prerequisite and basic guarantee for any country, which want to develop CE.

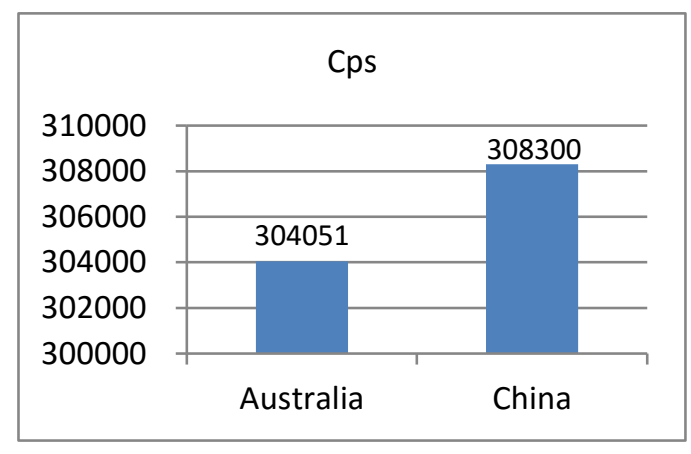

Fig. 3. Total comparison of Cps.

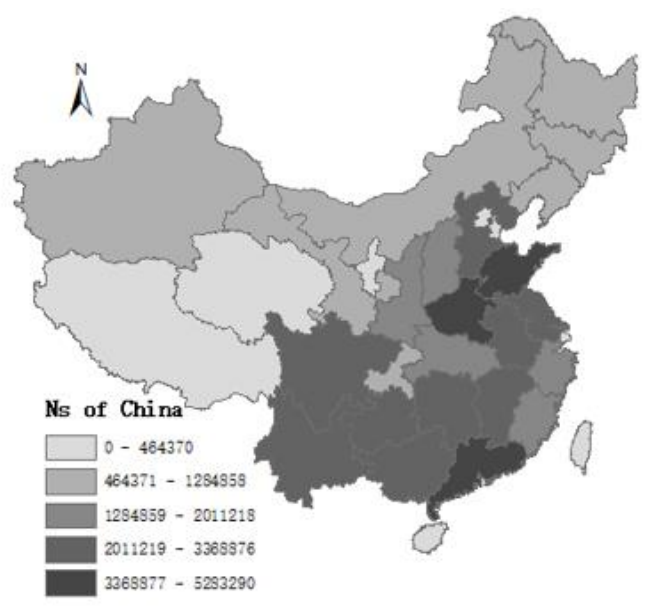

Fig. 4. A map of Ns in China.

Regional comparison of the two countries are displayed in Fig. 4 to 9. All maps are expressed in point density. Fig. 4 is the population distribution map of the provinces of China, and Fig. 5 is the population distribution map of the provinces of Australia. The distribution of the population is affected by a variety of factors, such as climate, altitude, hydrology, vegetation, soil, mineral resources and other natural factors, but 
also affected by economic, population and other human factors. Fig. 4 and Fig. 5 show that the population distribution of two countries on the whole is greater in the East than in the West, China's western and northwestern populations are relatively small, especially in Xi Zang, Xin Jiang, Qing Hai, Gan Su and Inner Mongolia, the population distribution in these areas is small and scattered. The eastern region in China, especially the coastal areas, such as Henan, Hebei, Jiangsu, Guangdong and other developed areas, have larger populations. While Australia has a relatively small population in the central region, mainly the Northern Territory and South Australia, The population of these two states is mainly governed by natural circumstances.

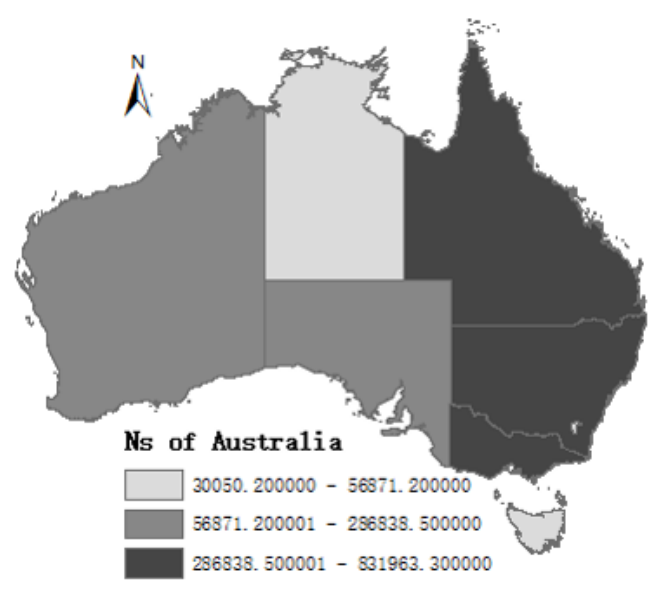

Fig. 5. A map of Ns in Australia.

Fig. 6 is a regional distribution map of student to teaching Staff Ratio in China, and Fig. 6 is a regional distribution map of student to teaching Staff Ratio in Australia. Generally speaking, China's student to teaching Staff Ratio in CE is more dispersed in the east than in the West. The gap is big between the East and the west. The distribution of student to teaching Staff Ratio in the East and the west is imbalanced. This shows that the overall distribution of teacher resources in China is unbalanced distribution. Teachers' are in greater numbers in Inner Mongolia, Heilongjiang and Jilin provinces. But, the most scarce areas of teacher resources are Qinghai, Sichuan, Guizhou and Guangxi province of China. As a whole, the ratio of Australian students and teachers increases from the west to the east, the higher student to teaching Staff Ratio in the East, the lower student to teaching Staff Ratio in the west, and the largest student to teaching Staff Ratio area in New South Wales. In other words, there are plenty of teachers in Western Australia, and there is room for improvement in the number of teachers in the eastern region, especially in New South Wales. The distribution of teacher resources in China and Australia is also unbalanced, but the imbalance of teachers' resources in Chinese CE is much larger than that in Australia. Therefore, the regions with a higher ratio of teachers and students should actively 
introduce more teachers, expand the ranks of teachers, and promote the balanced development of teachers' resources.

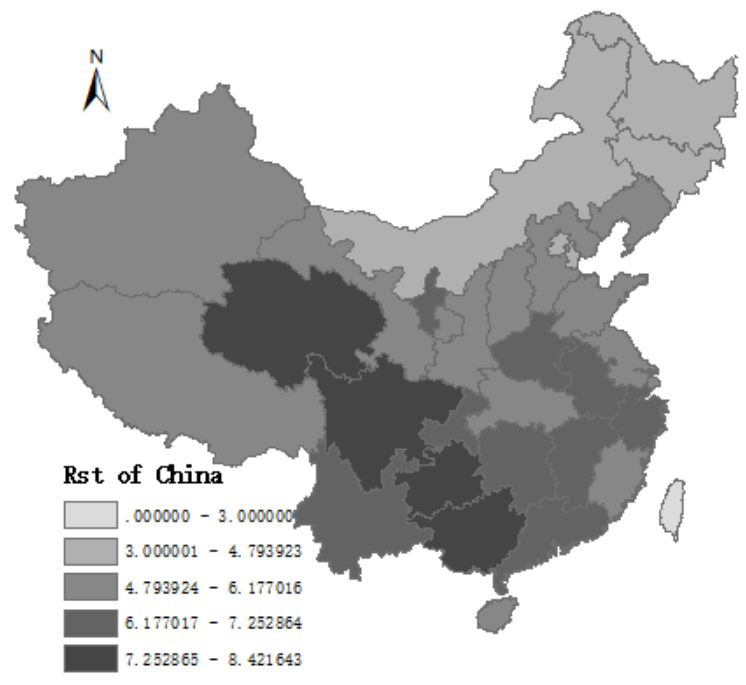

Fig. 6. A map of Rst in China.

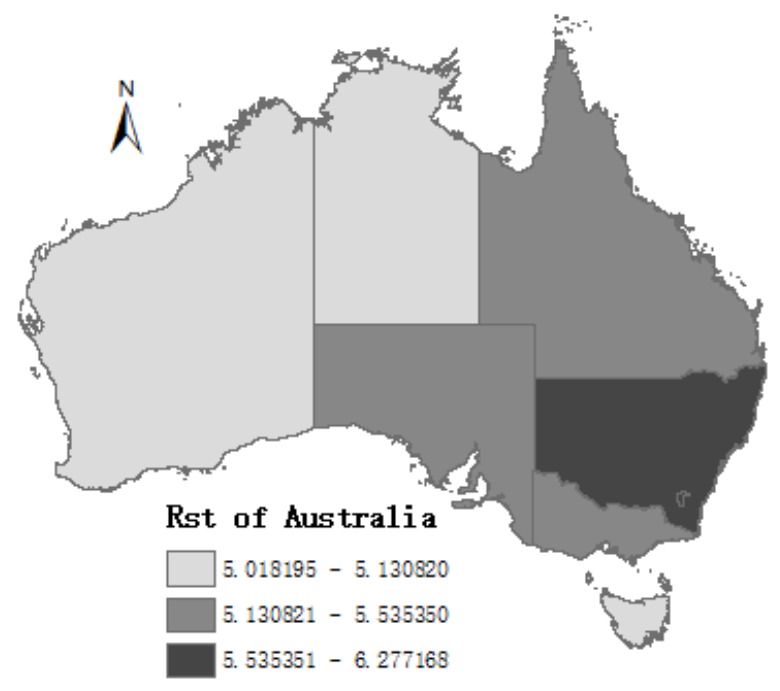

Fig. 7. A map of Rst in Australia. 


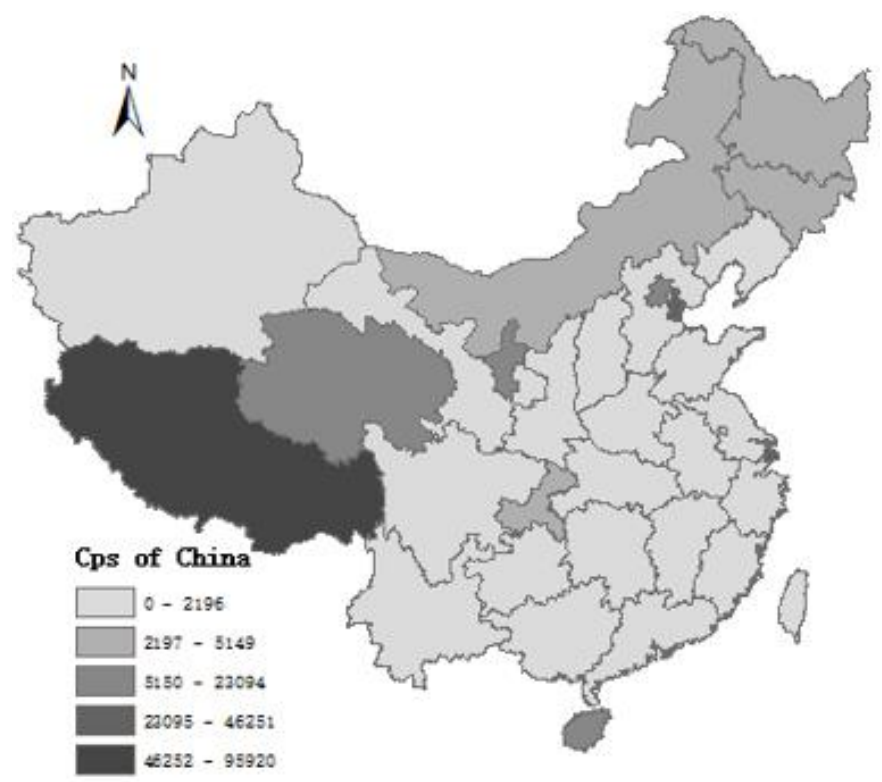

Fig. 8. A map of Cps in China.

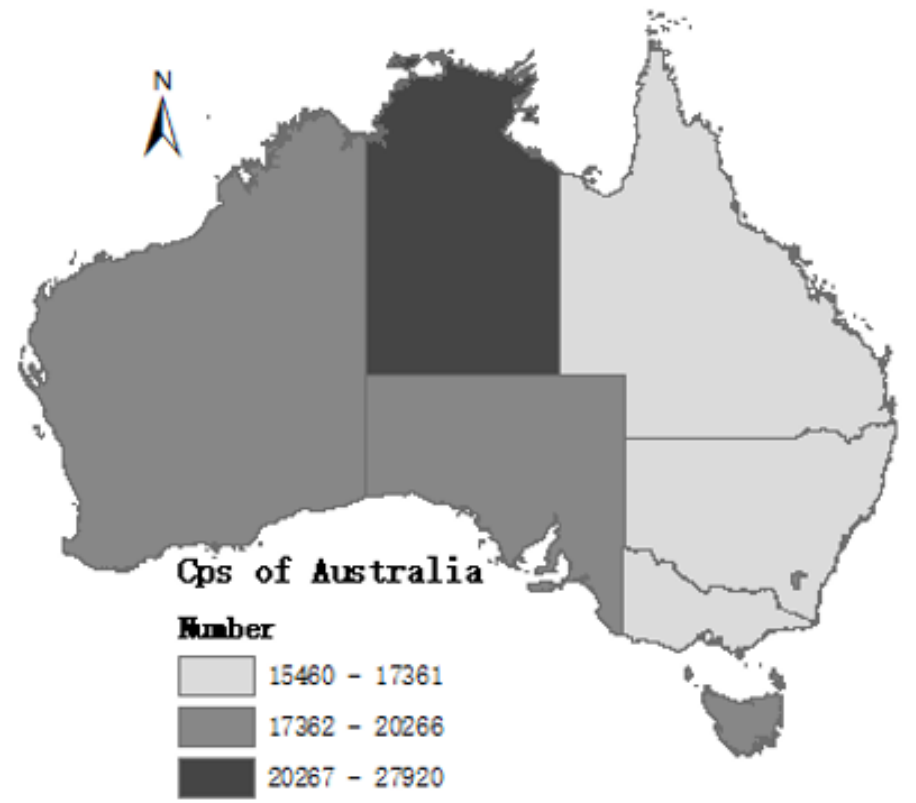

Fig. 9. A map of Cps in Australia.

Fig. 8 is a map of the distribution of CE funds per student in China. Fig. 9 is a map of the distribution of CE funds per student in Australia. In the northern and eastern 
regions of China, the distribution of funds is relatively balanced, but there is a large gap in the inner of western region. For example, Xinjiang and Tibet are both frontier minority areas in China, but the funds for CE in Tibet are the highest in the country, the Xinjiang is the lowest, this is obviously not conducive to the development of compulsory education in the western region. If the government does not adjust the support program, the gap between compulsory education in the western region will become more and larger, and this gap will inevitably affect the overall development of compulsory education in the country.

The Chinese government should focus on the current situation of CE in Xinjiang, increase supporting and promote balanced development in the western region of China.

Because of poor natural environment and lower population in the western region in Australia, there is more investment in the western region of Australian education, less investment in the western region. As can be seen from Fig. 9, the population and the number of students in the North Territory are the least, but the investment in the northern territory of the Australian government is the most, which indicates that the Australian government has already realized the insufficient development of compulsory education in the Northern Territory to increase investment and make the compulsory education of the Northern Territory develop as fast as possible. So the Australian government focuses on supporting the western region, which not only conforms to the law of natural development, but also effectively promotes the overall development of CE in the whole country.

\section{Conclusions and Recommendations}

As an educational input of national behavior, CE has a fundamental responsibility to narrow regional gaps. The government should realized the coordinated development between regions. It is also an important way to realize the function of CE.

From what have been discussed, whether in Australia or China, the regional differences in the development of compulsory education is large, in other words, the regional differences in compulsory education cannot be ignored by governments and researchers. As we all know, the relationship between education and economic development has been recognized by the public. The distribution of population is influenced by many factors, such as physical environment and historical development factors. While paying attention to the development of $\mathrm{CE}$, we have to focus on the influence of the geographical environment and human environment on the development of CE. The overall development of national CE depends on the development of various regions, and the development of regional $\mathrm{CE}$ can promote overall development. Therefore, we should not abandon regional development to focus on overall development, and the region and the whole are interrelated and interrelated.

At the same time, there is no doubt that optimizing the allocation of resources is the basis and guarantee for realizing the regional equilibrium of $\mathrm{CE}$. Influenced by 
historical and natural environment, the difference of the economic and social development between China and Australia has led to a substantial difference in the spatial distribution of CE in two countries and the unbalanced development of the CE in the East and the west, and the two countries should pay more attention to the optimal allocation of regional $\mathrm{CE}$ resources which are lagging behind.

\section{$5 \quad$ References}

[1] Wang H. (2003). A study of the history of compulsory education in China. Thesis. Northwest Normal University.

[2] Filiztekin, A. Karahasan, C. (2015). Compulsory schooling and geographic distribution on voluntary education. ERSA conference papers. European Regional Science Association.

[3] Sun X. (2006). Revision of the compulsory education law: background, process and major breakthrough. Research on the development of Education, 15: 11-17.

[4] Wu J., Song X. (2017). Research on regional differences and spatial pattern evolution of Teacher Allocation in Compulsory Education -an example from Shanghai. Macro quality research, 5(2): 108-118.

[5] Ministry of Education of the People's Republic of China.Notice of the Ministry of education on strengthening the management of basic education. 2002. http://old.moe.gov.cn/publicfiles/business/htmlfiles/moe/moe 1793/201006/88981.html

[6] Ministry of Education of the People's Republic of China.Opinions of the Ministry of education on implementing Scientific Outlook on Development to further promote the balanced development of compulsory education. 2010. http://www.moe.gov.cn/srcsi te/A06/s3321/201001/t20100119 87759.html

[7] Ministry of Education of the People's Republic of China.National medium and long term education reform and development plan outline (2010-2020). 2016.

[8] Ministry of Education of the People's Republic of China.The decision of the State Council on speeding up the development of Ethnic Education. 2015.

[9] Wazzan, K. (2017). The spatial distribution of the basic education schools in lattakia city (syria). Journal of Educational \& Social Research, 7. https://doi.org/10.59 01/jesr.2017.v7n1p71

[10] Olga A. V. (2000). Spatial distribution of production and education. Documentos de trabajo - Analise Economica, 37(6), 1-21.

[11] Chris D. (1991). Re-vision and adaptation in post-compulsory education in australia. International Journal of Lifelong Education, 10(10), 325-344. https://doi.org/10.1 $\underline{080 / 0260137910100406}$

[12] Governments, C. O. A. (2009). National partnership agreement on youth attainment and transitions. Council of Australian Governments.

[13] Doherty, C. (2017). Edufare for the future precariat: the moral agenda in australia's 'earning or learning' policy. Journal of Education Policy, 32, 1-14. https://doi.org/10.10 $\underline{80 / 02680939.2016 .1215534}$

[14] Reid, Carol, and K. (2016). Watson. Compulsory Schooling in Australia. Palgrave Macmillan US.

[15] Carol R., Helen Y. (2012). The new compulsory schooling age policy in nsw, australia: ethnicity, ability and gender considerations. Journal of Education Policy, 27(6), 795-814. https://doi.org/10.1080/02680939.2012.664287 


\section{Authors}

Saidong $\mathbf{L v}$ is a lectuer of school of Tourism and Geographical Sciences, Yunnan Normal University, Kunming, 650500, China. (E-mail: saidonglv@ynnu.edu.cn). She currently works in Key Laboratory of Education Informatization for Nationalities of Ministry of Education, Kunming, 650500.

Yujun Pan is a professor of school of Tourism and Geographical Sciences, Yunnan Normal University, Kunming, 650500, China. (E-mail: 13888346995@139.com). He is in leardship in Key Laboratory of Education Informatization for Nationalities of Ministry of Education, Kunming, 650500.

Article submitted 2019-09-19. Resubmitted 2019-10-17. Final acceptance 2019-10-18. Final version published as submitted by the authors. 